\title{
Considerações sobre a aprendizagem da performance musical
}

\author{
Daniel Lemos Cerqueira (Universidade Federal do Maranhão, São Luís, Maranhão) \\ dal_lemos@yahoo.com.br \\ Ricieri Carlini Zorzal (Universidade Federal do Maranhão, São Luís, Maranhão) \\ riciviolao@terra.com.br \\ Guilherme Augusto de Ávila (Universidade Federal do Maranhão, São Luís, Maranhão) \\ guilherme_violao@hotmail.com
}

Resumo: Este artigo oferece uma proposta para fundamentação da prática musical de instrumentos e canto, enfatizando procedimentos de estudo, baseando-se principalmente na Teoria da Aprendizagem Pianística de José Alberto Kaplan. Paralelamente, foi realizada uma breve releitura crítica da história do ensino de instrumentos musicais e métodos para educação musical, em diálogo com áreas afins à Performance Musical, entre elas Psicologia Cognitiva, Neurociência e Educação Física.

Palavras-chave: Performance Musical; Pedagogia; Transdisciplinaridade; Modelo de Aprendizagem; José Alberto Kaplan.

\section{Considerations about music performance learning}

Abstract: The present work offers a systematized proposal for the practice of musical instruments and singing, emphasizing study procedures. The main basis for this work is the Pianistic Learning Theory (Teoria da Aprendizagem Pianistica) by Brazilian pedagogue José Alberto Kaplan. There is also a brief critical overview of the history of musical instrument learning and music education methods, dialoguing with areas such as Cognitive Psychology, Neuroscience and Physical Education.

Keywords: Music Performance; Pedagogy; Transdisciplinarity; Learning Model; José Alberto Kaplan.

\begin{abstract}
1. Introdução
0 trabalho dos instrumentistas, desde os primórdios da existência humana, é semelhante à profissão do artesão, que trabalha individualmente em sua casa a matériaprima, moldando-a cautelosamente até a elaboração do produto final. Este tipo de ofício requer contato íntimo com o objeto, dedicação de tempo, atenção a detalhes, cuidados estéticos, e por assim ser, é dotado de um viés artístico, personificando uma identidade cultural. Outra semelhança é a forma de transmissão do saber que, no Artesanato, ocorre de pai para filho de forma empirica e não-escrita. Da mesma forma na Música, há a relação entre mestre e aprendiz, cuja transmissão de conhecimentos ocorre no percurso até a preparação final do repertório que se deseja apresentar (HARNONCOURT, 1988, p.29). Porém, o processo de aprendizagem do Artesanato passou
\end{abstract}

por profundas alterações, especialmente na Idade Média, com sua inclusão em institutos técnicos e currículos universitários tecnológicos. RUGIU comenta sobre este acontecimento:

\footnotetext{
Os conteúdos e métodos e, ainda mais, a ideologia, que será depois transmitida nas escolas ou universidades públicas, serão, em muitos aspectos, opostos e antagônicos em relação àqueles da formação artesã de antigamente. Nem as modernas formas de instrução e treinamento profissional podem-se considerar a continuação dos antigos modelos artesanais. Estes, do aprendizado de antigamente, têm só o nome, não mais que isso. (RUGIU, 1998, p.25)
}

Assim sendo, no caso do artesanato, a aplicação de metodologias de ensino modernas baseadas em premissas científicas, características do modelo acadêmico, vieram a substituir o modelo tradicional de ensino principalmente 
a partir do Século XVII, descaracterizando a veia artística do ensino de até então. Logo, a questão fundamental que deve estar no foco de pesquisadores que pretendem refletir sobre o ensino musical na academia é: como a Ciência pode contribuir para o ensino de Música, preservando as características essenciais da Arte?

\section{História do Ensino de Instrumentos Musicais}

Até o século XVIII, o ensino de instrumentos musicais se concentrava nas premissas expostas anteriormente, com a transmissão de conhecimentos baseada no empirismo e na tradição oral através da relação entre mestre e aprendiz. Esta maneira de ensinar foi incorporada pela metodologia de aulas individuais para instrumentistas, considerada por muitos até hoje a forma mais eficaz de ensino por permitir a transmissão de uma ampla variedade de informações lógicas, intuitivas e psicomotoras, exigidas na prática instrumental. Vários trabalhos sobre a prática de estudo individual foram publicados desde 1700, baseados em experiências empíricas e pessoais, além de opiniões dos autores sobre este assunto (Jørgensen, citado por WILLIAMON, 2004, p.87)

No século XIX surgiu o ensino formal de Música a partir de instituições denominadas conservatórios ${ }^{1}$, cujo modelo referencial fora o Conservatório de Paris, criado após a Revolução Francesa. Estas instituições visam à formação de músicos "executantes" e "virtuoses", aptos para a performance em salas de concerto, e para este fim, adotam uma prática de ensino tecnicista, com a utilização de repertório baseado na música europeia tradicional². Algumas instituições adotaram a denominação "Escola de Música", mas apesar de sugerir uma ideia de modernização, em grande parte delas o ensino continuou alicerçado sob os mesmos pressupostos.

A metodologia de ensino dos conservatórios possui, comumente, um período precedente de introdução à teoria musical, e ao iniciar o estudo do instrumento, é apresentado um rígido programa (ou repertório) a ser seguido $^{3}$, baseado em níveis progressivos de dificuldade. Os critérios utilizados para definir este repertório não se baseiam em premissas sólidas e científicas, sendo até contraditórios se examinados sob determinados aspectos, como dificuldade de coordenação motora, leitura ou entendimento musical (KAPLAN, 1987, p.95-103). Assim, não era o repertório que se adaptava ao aluno, mas o contrário: ele deveria se adequar às exigências do programa, sem considerar sua experiência musical prévia, suas características fisiológicas e habilidades motoras ${ }^{4}$. Quanto ao professor, não havia espaço para o exercício da crítica sobre a execução instrumental - habilidade fundamental para todo músico, mencionada como "autocrítica" por KAPLAN (1987, p.40) e denominada Audição Crítica por FISHER (2010, p.124-125), não contemplada na abordagem tradicional da disciplina Percepção Musical - restando-lhe apenas o papel de transmitir um conhecimento "condicionado". ESPERIDIÃO analisa esta metodologia:
Ao aluno compete adquirir as habilidades necessárias para a execução instrumental em detrimento de uma educação musical que contemple o indivíduo como um ser atuante, reflexivo, sensivel e criativo. Ao professor compete a responsabilidade de transmitir os saberes e os conhecimentos durante o processo de aprendizagem. (ESPIRIDIÃO, 2002, p.70)

Neste modelo, tanto aluno quanto professor não possuem liberdade para exercer reflexões críticas e criativas durante o processo de aprendizagem, fato que reforça a ausência de outro aspecto fundamental da aprendizagem: a motivação, reforçados por KAPLAN (1987, p.60-63), COSO (1992, p.18-22), 0'Neill e McPherson (citados por PARNCUTT e MCPHERSON, 2002, p.31-32). Diante da rigidez do programa, o professor tem poucas alternativas que incentivem o interesse do aluno. FUCCI AMATO reforça:

$\mathrm{Na}$ pedagogia tecnicista adotada pelos conservatórios, a qual não se define como um método de ensino musical criativo e sensivel, professor e aluno ocupavam uma posição secundária, de executores de um programa cuja concepção, planejamento, coordenação e controle estavam a cargo de especialistas habilitados. (FUCCI AMATO, 2006, p.77)

A ausência de motivação é evidente neste modelo pedagógico, sendo um problema comprometedor devido ao alto nível de dedicação necessário para o aprendizado de um instrumento musical. Ainda, se a postura do professor for a de sempre corrigir os aspectos negativos da interpretação, sem reforçar pontos positivos e aparentes melhoras, o aluno poderá interpretar como falta de progresso e incapacidade, levando-o à desmotivação (KAPLAN, 1987, p.67).

Considerando tais questões, fica evidente o despreparo metodológico e curricular de conservatórios que adotam o supracitado sistema, tanto por não considerar teorias modernas da Pedagogia quanto em preparar do aluno para inserção na atual conjuntura históricocultural, especialmente em questões sobre inclusão social e demanda profissional. Ainda, por mais que estejam dispostos a reformular futuramente sua metodologia de ensino, os músicos formados por estas instituições apresentam desconforto na adoção de novos modelos, tendendo a repetir os pressupostos pedagógicos vivenciados devido à carência de subsídios e informações relativas que tratem sobre o ensino da Performance Musical (GLASER et al, 2005, p.28). Sob tal perspectiva se encontram grande parte dos professores das instituições de ensino musical, partidários de uma visão tradicionalista e possuidores de hábitos de estudo já consolidados, contribuindo para perpetuar os valores do sistema pedagógico em questão.

\subsection{Métodos de ensino}

Até o Século XVIII, os métodos de ensino da Performance Musical - até então trabalhados em contexto de ensino nãoformal - possuiam uma abordagem interdisciplinar, onde o aluno aprendia o repertório do instrumento juntamente com as demais áreas do saber musical fragmentadas no ensino formal da atualidade, como Percepção Musical, Contraponto, Harmonia e História da Música, entre 
outras (CERQUEIRA, 2011, p.7). Ainda, eram desenvolvidas habilidades como improvisação e transposição, não contempladas no ensino formal de Música até os dias de hoje. Curiosamente, tais métodos estão mais próximos dos princípios provindos das modernas teorias científicas de aprendizagem musical do que grande parte do material didático elaborado posteriormente.

A partir do século XIX, com o surgimento dos conservatórios, o ensino da Performance Musical passou a se basear na execução de repertório a partir de níveis crescentes de dificuldade motora. Entretanto, com a fragmentação do conhecimento presente neste modelo pedagógico - herdada do modelo de academia - surgiram diversos problemas, entre eles o estudo da técnica instrumental fora do repertório (escalas e arpejos, por exemplo) e a consequente descontextualização de seu sentido musical ${ }^{5}$. Outro problema era tratar o conhecimento de forma isolada, sem estabelecer relações entre as diversas disciplinas do currículo e o ensino do instrumento, restando ao aluno conectá-las caso conseguisse. 0 comentário seguinte ilustra a imagem que se tem na atualidade sobre esta prática pedagógica:

A velha relação entre mestre e aprendiz foi abandonada e tudo o que tem a ver com elocução - que requer o entendimento - foi eliminado. Atualmente, estes conservatórios exercitam técnicas de performance ao invés de ensinar música como linguagem. (LAWSON et al, 1999, p.152)

Apesar de ter provido a formação de instrumentistas durante mais de um século, esta prática de ensino - qualificada como de caráter autoritário e pertencente à corrente psicológica behaviorista por Uszler (citada por USZLER et al, 2000, p.256) não mais está adequada às necessidades histórico-culturais da atualidade. Pode-se afirmar que o ensino artístico da Performance Musical - como era realizado anteriormente ao surgimento do ensino formal de Música - só chegou aos dias de hoje graças à prática pedagógica não-formal que continuara paralelamente aos conservatórios. No caso específico do Piano, grandes intérpretes e professores como Franz Liszt (1811-1886) e Theodor Leschetizky (18301915) mantiveram esta prática, formando e influenciando pianistas de renome do início do século XX (Gordon, citado por USZLER et al, 2000, p.292). Ainda, professores de conservatório davam aulas em estúdios particulares a alunos que se interessavam no estudo exclusivo do instrumento, e não em cumprir a grade curricular do conservatório (Bomberger, citado por PARAKILAS, 2001, p.129. Era comum que Liszt, em suas master-classes, fizesse caricaturas de famosos professores de conservatório. Ainda, perguntava a alunos que apresentavam execuções rígidas e sem inventividade musical se eles estudavam em algum conservatório nas proximidades (Bomberger, citado por PARAKILAS, 2001, p.131-132).

Com o reconhecimento da linha de pesquisa em Educação Musical no final do século XIX, questionamentos e reflexões acerca das propostas pedagógicas do modelo tecnicista de ensino se tornaram mais frequentes. Assim, no início do século $X X$, surgiram os "métodos ativos", visando a um ensino musical dinâmico e que providenciasse contato efetivo com a vivência e o fazer musical. Dentre nomes de destaque nesta corrente, podemos citar Maurice Martenot, Carl Orff, Zoltán Kodály, Heitor Villa-Lobos, Jacques Dalcroze, Edgar Willems, Shinichi Suzuki, HansJoachim Koellreutter, Keith Swanwick e Edwin Gordon. Suas ideologias poderiam ser integradas aos cursos de Performance Musical, porém, instituições especializadas no ensino de Música apresentam resistência em adotar estas ideias (FONTERRADA, 2005, p.108), salvo no caso do método Suzuki, analisado em seguida. Dessa forma, tais abordagens acabaram se tornando mais presentes no ensino musical voltado à escola regular, graças às variadas possibilidades de aplicação metodológica e elaboração de atividades. Ainda, na atualidade, reforçase a conjuntura político-educacional favorável, com a inserção da Música como conteúdo obrigatório na disciplina de Artes (BRASIL, 2008). Porém, o enfoque presente nos cursos de Licenciatura em Música não fornece subsídios para o ensino da Performance Musical. Portanto, esta habilitação não constitui uma alternativa a quem deseja se capacitar no ensino de instrumentos e canto (GLASER et al, 2005, p.45).

Paralelamente, próximo à segunda metade do Século $X X$, Shinichi Suzuki desenvolveu seu método, amplamente adotado em instituições tradicionais de ensino musical por oferecer semelhança com os pressupostos pedagógicos já adotados neste contexto. 0 alicerce do método Suzuki é tratar a Música como uma linguagem, buscando inserir o aluno em um universo do repertório europeu tradicional, mas para isto, evita que o mesmo possua contato com a música de outras culturas, artificializando sua experiência musical ${ }^{7}$. Logo, o autor sugere a atuação dos pais na educação, providenciando ao aluno um ambiente onde haja a apreciação da "boa música" (SUZUKI, 1998, p.7), julgamento de valores típico de ideais tradicionalistas e eurocêntricos. Porém, um aspecto importante observado nesde método é considerar que o indivíduo é "fruto de seu meio" (SUZUKI, 1998, p.3), podendo qualquer um aprender música, descartando o talento como elemento essencial à aprendizagem ${ }^{9}$. Dessa forma, o aprendizado musical é baseado na aquisição progressiva de habilidades motoras, sob a finalidade de se expressar musicalmente (SUZUKI, 1998, p.9). Outro aspecto significativo são as estratégias de motivação adotadas, oferecendo condições para que o aluno veja seu desenvolvimento e esteja em um ambiente musical semelhante tanto na aprendizagem quanto no cotidiano. Conforme exposto anteriormente, a motivação é um elemento fundamental do processo de aprendizagem, sendo tema de diversas pesquisas na área de Psicologia Cognitiva e Psicanálise, além de não ser considerada pelo ensino tradicional da Performance Musical ${ }^{10}$. Trata-se, portanto, de uma caracteristica que certamente contribuiu para a aceitação deste método, pois em relação às metodologias de ensino da Performance Musical anteriores, os resultados são evidentes. 


\subsection{Teoria da Aprendizagem Pianística}

Desenvolvida por José Alberto Kaplan (1935-2009), pianista e compositor argentino radicado no Brasil, é um guia instrucional embasado cientificamente sobre diversos elementos necessários para a interpretação instrumental. Mesmo tratando de obras para piano e seus aspectos idiomáticos, os princípios expostos sobre Fisiologia, Anatomia, Psicologia e aprendizagem musical podem ser aplicados ao estudo dos instrumentos musicais em geral.

A teoria em questão procura expor uma forma de aplicação consciente do conhecimento por parte do professor, aplicando-a ao repertório que se deseja estudar e à metodologia das aulas, segundo bases científicas provindas de diversas áreas do conhecimento. KAPLAN afirma que este é o principal objetivo de seu trabalho:

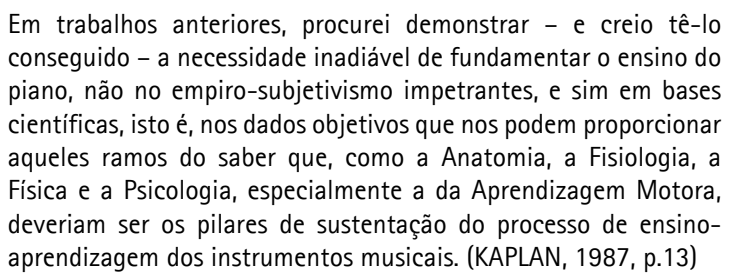

Trata-se de uma contribuição significativa ao ensino da Performance Musical no Brasil, providenciando ao professor de instrumento ferramentas científicas que solidificam sua prática pedagógica. Nesse aspecto, o diálogo com as áreas de Psicologia Cognitiva e Aprendizagem Motora providenciaram informações preciosas para a prática instrumental. Por exemplo, o processo de aprendizado das habilidades motoras - ações musculares conscientemente aprimoradas que são internalizadas na forma de movimentos automatizados ${ }^{11}$ - é de origem psicológica (KAPLAN, 1987, p.14), e não de força ou destreza muscular, como há muito se entendera por técnica instrumental. Esta concepção altera todo o planejamento pedagógico do ensino da Performance Musical, uma vez que as estratégias de estudo tem por objetivo específico o desenvolvimento da técnica, fato refletido na escolha do repertório e material didático. Dessa forma, a aplicação de conceitos da Psicologia Cognitiva se mostra consideravelmente esclarecedora para a compreensão dos processos envolvidos na prática instrumental.

Outra questão relevante é a ideia de que a execução de instrumentos musicais é um fenômeno complexo, requerendo uma série de habilidades e conhecimentos atuando simultaneamente. Podemos mencionar a Fisiologia, Neurociência, Psicologia, Educação Física (Aprendizagem Motora), Percepção Musical (Audição Crítica), Organologia e Repertório, Acústica, Composição (Análise Musical), História e Antropologia, entre outros. Luciano Berio, compositor italiano, compartilha desta visão, afirmando que o virtuosismo provém da complexidade de uma obra musical, envolvendo o conflito entre a ideia musical, o instrumento e a capacidade de personificar estilos e períodos musicais distintos e trazê-los ao presente, dialogando com o passado (Berio, citado por DALMONTE, 1988, p.76-77). Logo, a imagem do instrumentista ou cantor como um "homem alienado com dedos ágeis e cabeça vazia ${ }^{12 "}$ não condiz com 0 conhecimento necessário à interpretação instrumental, muito menos com sua relevância na manutenção do patrimônio cultural e histórico da Humanidade.

\section{Modelo de Ensino e Aprendizagem da Performance Musical}

Este modelo é baseado principalmente nos conceitos expostos em Teoria da Aprendizagem Pianística, com inserção de novos conceitos e algumas alterações. 0 nome "Ensino e Aprendizagem da Performance Musical" foi escolhido por representar mais efetivamente 0 processo descrito, que envolve as etapas de preparação (ou aprendizado) e a performance (apresentação pública). Este modelo pode servir de guia tanto para professores - em busca de soluções para os problemas de seus estudantes - quanto a intérpretes, que podem elaborar um planejamento de estudo consciente e eficaz, pois ao conhecer o processo de aquisição das habilidades musicais, é possivel adotar estratégias que acelerem a aprendizagem do repertório. Todavia, é necessário reforçar que, assim como na maioria das pesquisas em Performance Musical segundo Barry e Hallam (citadas por PARNCUTT e MCPHERSON, 2002, p.152), o presente modelo foi elaborado com base na prática memorizada da música de concerto, sendo necessário avaliar sua aplicabilidade em outros contextos e estilos musicais. Ainda, é preciso direcionar as pesquisas para que o modelo contemple o desenvolvimento de outros tipos de habilidades coerentemente ${ }^{13}$, como leitura à primeira vista ou improvisação ${ }^{14}$, por exemplo. Tendo estas questões em mente, seguem alguns princípios para melhor compreensão do modelo a ser exposto.

Como forma de representar a complexidade do processo de aprendizagem e execução de instrumentos musicais, é preciso entender que a separação dos conceitos envolvidos ocorre apenas para fins teóricos, pois em qualquer situação prática, todas as atividades ocorrem de forma simultânea. Ao estudar uma peça, por exemplo, são trabalhadas a postura corporal e a posição mais apropriada das mãos no instrumento, juntamente com o processo de leitura, análise e memorização da peça. Da mesma maneira, não pode haver o aprendizado do instrumento musical sem 0 intermédio de uma obra musical ou repertório. 0 estudo do instrumento restrito ao mero objetivo de desenvolver habilidades motoras é um equívoco metodológico que interfere negativamente no trabalho do executante, restringindo sua prática instrumental apenas à aquisição de habilidades que podem não ser úteis se aplicadas a contextos musicais específicos:

0 estudo dos chamados "problemas técnicos" - o caso antes apontado dos Exercicios e Estudos criados para "resolvê-los" e, especialmente, a exercitação de escalas e arpejos separados do conteúdo onde se encontram inseridos - cria uma série de estereótipos psicomotores que, na maioria dos casos, em lugar de beneficiar o aluno, o 
prejudica. Esses estereótipos, verdadeiros "modelos" se fixam de tal maneira no sistema psicomotor do indivíduo, que "obscurecem" até a capacidade e a imaginação do executante de encontrar soluções "não ortodoxas" para as passagens que, se digitadas de acordo com os "modelos" aprendidos se tornam mais dificeis de ser realizadas. (KAPLAN, 1987, p.92)

Sendo assim, é fundamental que o instrumentista realize um estudo consciente das diversas variáveis presentes na prática instrumental, direcionando sua concentração de forma eficiente ao aspecto que deseja trabalhar, utilizando as ferramentas de estudo que julgar necessárias e buscando a realização da passagem de acordo com sua interpretação musical. Cada obra é um estudo de caso, com inúmeras combinações possíveis de articulações musicais e motoras. Logo, a postura que deve ser adotada pelo intérprete é de raciocínio crítico, uso eficiente da concentração e reação às dificuldades que porventura aparecerem, ao invés da adoção de padrões estereotipados e generalizadores.

No Ex.1, abaixo, apresenta-se a imagem do modelo para que sejam introduzidos os demais conceitos.

A estruturação do modelo demonstra a interrelação entre os diversos conceitos presentes na prática instrumental, e para entendê-los, é necessário reforçar novamente que nenhum elemento pode ser compreendido de forma separada. Se adotarmos uma estratégia de ensino que reforce a "memória", por exemplo, devemos considerar suas relações com a "consciência" - a memória lógica e auditiva - e com o "movimento" - a memória cinestésica e visual. Caso o estudo não contemple todos os tipos de memorização, poderá haver fragilidade ou falha no armazenamento das informações, fato que pode causar problemas na apresentação pública devido à Ansiedade na Performance, transparecendo então as falhas do processo de preparação ${ }^{15}$. Logo, todo estudo mal direcionado é aquele que não abrange a completude dos elementos envolvidos no modelo. Voltando ao exemplo supracitado, um estudo concentrado apenas na aquisição de habilidades motoras e na automatização ou seja, nas relações entre "movimento" e "memória", sem contemplar a "consciência" - não permite uma memorização sólida, e além de não oferecer preparo para uma performance segura a curto prazo, impede um desenvolvimento mais completo das habilidades musicais a longo prazo.

Considerando tais questões, segue agora uma explicação visual do modelo apresentado. No centro temos a "Performance", que representa o produto final do processo - entendido aqui como o momento de apresentação pública. Trabalhando para sua consolidação, há o "movimento", a "memória" e a "consciência", três dimensões correlacionadas de atividade. Como forma de trabalhá-las, temos as "ações", presentes nas circunferências, cuja orientação representa os elementos no qual se iniciam e finalizam. Temos ainda os "elementos de retenção", presentes nas circunferências em letras negras. Por último, há as etapas de "estudo" e "execução", representando a porção da circunferência onde se concentra um maior reforço destas etapas.

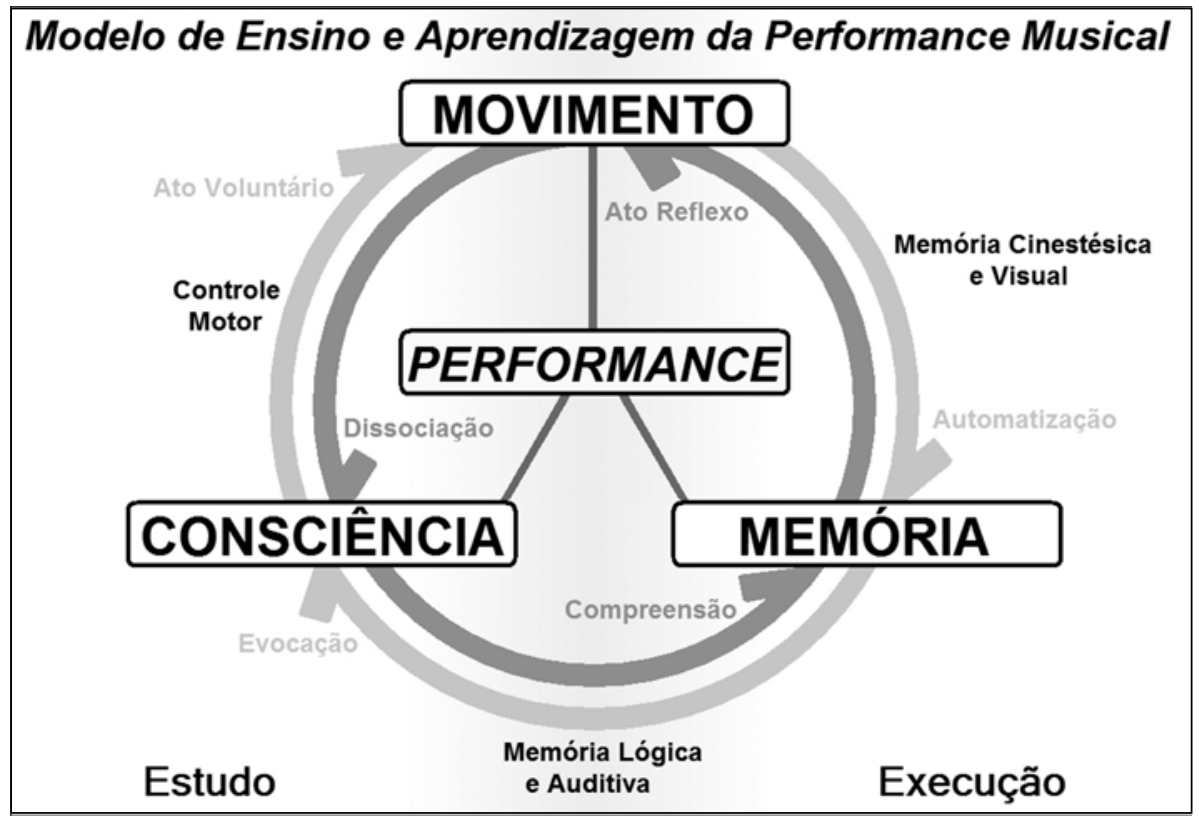

Ex.1 - Modelo de Ensino e Aprendizagem da Performance Musical 
Outro fato importante a ser entendido é que determinadas ações começam em um elemento de atividade (memória, consciência ou movimento) e se finalizam em outro. 0 ato voluntário, por exemplo, parte inicialmente de um comando do cérebro (consciência) que se transforma em uma resposta motora (movimento). A seguir, são apresentadas explicações mais detalhadas sobre cada conceito envolvido no modelo:

3.1 Elementos de atividade: correspondem aos modos de processamento das informações pelo mecanismo de assimilação (sistema de entrada ou input) e resposta (sistema de saída ou output), presentes na prática instrumental (KAPLAN, 1987, p.21-24). São eles:

Movimento: deslocamento do corpo no espaço ou alguns de seus segmentos (KAPLAN, 1987, p.29). Neste elemento são abordadas questões como postura, tensão muscular, dissociação, automatização, desenvolvimento de habilidades motoras, dedilhado ou digitação e particularidades fisiológicas do executante (KAPLAN, 1987, p.17).

Memória: armazenamento das informações adquiridas através de estímulos internos e externos ${ }^{16}$, podendo ser ordens de movimento automatizadas ou saberes racionais e intuitivos. Pesquisadores da Psicologia Cognitiva sugerem haver três modos de armazenamento da memória: sensorial - adquire informações provindas dos sentidos, curta - armazena dados por um curto período, e longa - armazena dados por tempo ilimitado. Esta última retém informações de procedimentos (aprendizagem motora), significados (motivos, temas ou figuras sonoras) e episódios (forma musical), residindo aqui todo o conteúdo necessário à prática instrumental (Ginsborg, citada por WILLIAMON, 2004, p.124-125).

Consciência: intervenção voluntária do indivíduo no processo, referindo-se a ações internalizadas ou atividades mentais ${ }^{17}$. Altera os demais elementos de atividade de acordo com a descoberta de novas digitações, tipos de toque, sonoridades e concepções da obra musical, por exemplo. É importante reforçar que tanto razão quanto intuição são consideradas formas de conhecimento (estes conceitos serão tratados adiante).

3.2 Elementos de retenção: dizem respeito aos tipos de informação armazenadas na memória longa, através do estudo. É importante reforçar que para a Psicologia Cognitiva e a Neurociência, a memória é única. Quando a classificamos em "cinestésica", "visual" ou "auditiva", por exemplo, nos referimos de fato aos tipos de informação armazenados, sendo que seu registro no cérebro ocorre por associação (SPRENGER, 1999, p.49-50). Assim, manteremos esta terminologia para estabelecer relações com a literatura de Pedagogia da Performance musical. Numa execução qualquer, por exemplo, um determinado movimento sempre será evocado juntamente com uma passagem musical específica, salvo em caso de mudança voluntária - pela consciência - desta associação pelo executante. Assim, uma memorização sólida é aquela onde o executante adquire o máximo de informações lógicas, cinestésicas, auditivas, etc. - possiveis da obra, relacionando e associando cada detalhe. Em seguida, apresentam-se os elementos de retenção:

Memória Cinestésica ${ }^{18}$ : armazenamento de informações relativas ao movimento (KAPLAN, 1987, p.69), que ficam retidas na memória longa de procedimentos. FISHER menciona ainda sua relação com a "memória tátil", que neste modelo pode ser compreendida associadamente ao presente tipo de informação sensorial (FISHER, 2010, p.39-40)

Memória Visual: retenção de informações provindas da visão. Na prática instrumental, trabalha a serviço da memória cinestésica, contribuindo para a automatização dos movimentos ${ }^{19}$.

Memória Lógica ${ }^{20}$ : entendimento das relações formais e estruturantes da obra, do estilo e da linguagem musical, sendo fixados e reconhecidos (KAPLAN, 1987, p.69) e associados ao conhecimento racional e abstrato (Ginsborg, citada por WILLIAMON, 2004, p.123-124). Assim, está associada à memória longa semântica - ou de significados. CHAFFIN reforça a importância da análise na identificação de padrões para a retenção do conteúdo musical (CHAFFIN et al, 2002, 67-69).

Memória Auditiva: fixação da linha melódica, objeto sonoro, sonoridade ou quaisquer elementos perceptíveis através da audição. Este tipo de informação se associa ao conhecimento intuitivo, pertencente à memória longa episódica. Nas práticas musicais de tradição não escrita, torna-se essencial para o aprendizado, pois a prática neste contexto requer percepção musical apurada e compreensão das estruturas musicais, reforçando assim a memória lógica (Ginsborg, citada por WILLIAMON, 2004, p.130-131).

Controle Motor: capacidade de coordenar os movimentos corporais de forma consciente (KAPLAN, 1987, p.55). Através de uma educação motora apurada e atenta, habilidades são adquiridas e evocadas cada vez que 0 executante trabalha um novo repertório. Entretanto, é necessário ter em mente que hábitos e vícios motores podem ser adquiridos, caso não haja conscientização sobre o estudo do movimento nas seções de prática, armazenando assim movimentos inadequados (CERQUEIRA, 2011, p.17). Este é um problema frequente no ensino informal de Música, pois neste contexto, é raro haver ciência sobre a importância do corpo na Performance Musical por parte do executante.

3.3 Ações: são as atitudes envolvidas no processo de aprendizagem e execução dos instrumentos musicais, tendo sua origem em um elemento de atividade e finalizando em outro, conforme a direção das setas presentes nas circunferências. Podem ser: 
Ato Voluntário: atividade motora desencadeada por um comando cerebral, ou seja, parte da consciência e termina no movimento. Relaciona-se diretamente às capacidades de controle motor do indivíduo em um determinado estágio de desenvolvimento.

Ato Reflexo: resposta motora condicionada que provém de algum estímulo. Origina-se na memória, expondo uma informação motora registrada - da memória ao movimento.

Dissociação: desenvolvimento da coordenação motora através de ações musculares conscientes, buscando maior eficácia e menor utilização muscular (economia de movimento). Assim, a ação motora torna-se controlada - do movimento à consciência. Este processo é fundamental para a assimilação de habilidades motoras (KAPLAN, 1987, p.37).

Automatização 21: armazenamento das informações de movimento através da ferramenta repetição, de forma análoga ao trabalho que atletas realizam para adquirir movimentos corporais (SCHMIDT e WRISBERG, 2008, p.48). Distingue-se do ato reflexo por ser produto de atitudes conscientes, sendo adquirida através do estudo ${ }^{22}$. Trata-se, portanto, do armazenamento de um movimento na memória - do movimento à memória.

Compreensão: entendimento das estruturas musicais, da forma, e consolidação de uma visão interpretativa da obra em questão - da consciência à memória. CHAFFIN reforça que dificilmente um músico não utilizaria seu conhecimento sobre forma musical para auxiliar na memorização de uma obra (CHAFFIN et al, 2002 p.71). Ainda, Lester (citado por RINK, 1995, p.197) defende que a interpretação é diretamente associada à compreensão musical, sendo um equívoco histórico tratar de análise musical e performance como se fossem objetos distintos, deixando de lado a íntima relação que possuem entre si.

Evocação: utilização de conhecimentos exteriores à obra que possam influenciar sua compreensão, como estilo musical, conceitos de análise musical, imagem sobre a personalidade do compositor, identidade histórico-cultural da obra e conhecimentos de prática instrumental préadquiridos, entre outros. Constitui, portanto, a experiência musical do executante, e quanto maior a quantidade de saberes pré-adquiridos, mais sólida será a memorização, pois haverá mais informações a serem associadas ao repertório estudado. Assim, inicia-se a partir de informações registradas - da memória à consciência.

3.4 Performance: é o produto final da prática instrumental. A fim de se obter uma diferenciação mais clara, é necessário expor a seguinte explicação conceitual: a performance é entendida como 0 ato momentâneo da apresentação musical, a execução como a segunda etapa de estudo (que envolve a performance) e a prática instrumental como todo o processo que envolve o trabalho do instrumentista, desde o aprendizado e aprimoramento do repertório, memória e movimentos até a apresentação pública (que contém a execução e, logicamente, a performance). CHAFFIN reforça a complexidade da performance, que envolve o controle de todos os aspectos musicais preparados, divididos em básicos - digitações, estruturas musicais, forma e interpretativos - dinâmicas, tipos de toque, tempo, fraseados (CHAFFIN et al, 2002, p.167).

3.5 Etapas de preparação: são as duas fases de preparação presentes no trabalho de prática instrumental, cada uma com objetivos distintos que, portanto, envolvem ferramentas de estudo particulares (KAPLAN, 1987, p.4041). São elas:

Estudo: primeira fase, concentrada na compreensão do repertório e aprimoramento ou evocação dos movimentos necessários à sua execução. A principal característica desta etapa é a necessidade de construir os elementos da memória, portanto, envolve prioritariamente consciência e movimento.

Execução: última fase, baseada na manutenção do repertório na memória e preparação para a performance. Requer ferramentas de estudo apropriadas para evitar a perda - esquecimento - de informações, tendo em vista a Ansiedade na Performance que ocorre nas apresentações públicas. SCHMIDT e WRISBERG (2008, p.56) afirmam que atletas em momentos de exposição psicológica apresentam redução das capacidades de concentração e controle motor, fato que pode ser associado à Ansiedade na Performance. Este assunto será tratado adiante.

\section{Ferramentas de Estudo}

Estas constituem o alicerce do estudo da Performance Musical, onde o executante aprimora as habilidades motoras necessárias para o controle do instrumento, conhece o repertório, prepara a performance e amadurece musicalmente. Apesar de sua fundamental importância, as razões da utilização de cada ferramenta não costumam ser definidas de forma mais clara e objetiva, fato que pode levar a seu emprego inadequado. Assim, a aplicação consciente de cada ferramenta contribuirá para aperfeiçoar a prática, contemplando todos os aspectos necessários à aprendizagem. Sendo assim, possuir maior consciência sobre como funcionam corpo e cérebro permite estabelecer estratégias de estudo mais sólidas e eficazes, fato reforçado por Jørgensen (citado por WILLIAMON, 2004, p.85) e CHANG (2009, p.16).

Outra questão acerca dos hábitos de estudo dos executantes - ainda fortemente presente na Performance Musical (Jørgensen, citado por WILLIAMON, 2004, p.89) - é a ideia da prática deliberada, onde se atribui o desenvolvimento musical à quantidade de horas praticadas diariamente. Em contrapartida, alguns autores defendem que a questão prioritária é consolidar estratégias eficazes de estudo, e entre eles, Gordon (citado por USZLER et al, 2000, p.270) e COSO (1992, p.17). Krampe e Ericsson (citado por RINK, 1995, p.87) afirmam que o tempo dedicado ao estudo deve se basear em condições satisfatórias de concentração, motivação e solução de aspectos performáticos não desejados. 
Dessa forma, seções prolongadas de prática levam a cansaço, redução da concentração e subsequente mau rendimento (CERQUEIRA, 2011, p.22-23) e até mesmo problemas fisiológicos (Gordon, citado por USZLER et al, 2000, p.270). Ainda, CHANG (2009, p.25) afirma que 0 tempo de descanso é fundamental, pois é neste momento que o cérebro desenvolve ligações entre os neurônios, adquirindo de fato as habilidades psicomotoras. Um acontecimento prático usual que ilustra esta ideia são os casos onde o executante fica alguns dias sem estudar uma determinada peça, e ao retomá-la, percebe uma melhora sensível. Este "ócio" costuma ser condenado por professores em instituições de ensino musical, pois provavelmente são adeptos da ideologia da prática deliberada e desconhecem o processo de aquisição das habilidades psicomotoras.

Logo, o executante deve optar por ferramentas que auxiliem na manutenção do repertório ou na solução dos problemas que se apresentam, de acordo com os objetivos da etapa de estudo pretendida. Falhas de memória, por exemplo, podem ser causadas quando o estudo privilegia apenas um dos tipos de memória (cinestésica e visual ou lógica e auditiva). Assim, é sugerida a opção por ferramentas que permitam a manutenção de ambas. Outro exemplo diz respeito a uma interpretação "mecânica" e sem expressividade, devendo o executante optar por ferramentas que trabalhem a compreensão musical - consciência. A seguir, são apresentadas algumas ferramentas de estudo, analisadas conforme o modelo em questão $0^{23}$ :

4.1 Ferramentas Gerais: são as técnicas de estudo que podem ser trabalhadas na aprendizagem de qualquer instrumento musical, adotando-se as devidas adaptações idiomáticas. A seguir, uma análise sobre algumas destas ferramentas:

Análise dos recursos fisiológicos: definição das digitações ou dedilhados mais adequados para executar as passagens musicais da obra, para instrumentos que utilizam os dedos (piano, violão, harpa, trompete, trompa, madeiras e cordas friccionadas, por exemplo), golpes de arco para cordas friccionadas, técnicas manuais aplicadas à percussão, entre outros. Resume-se à utilização eficiente do corpo na Performance Musical, a partir do desenvolvimento da consciência corporal e do controle motor. Como recurso, é essencial para o trabalho inicial do repertório, sendo recomendado como a primeira ferramenta a ser utilizada. Envolve, assim, uma análise prévia da peça por trechos pequenos, conhecendo-a e escolhendo as opções mais adequadas de movimentos. Quanto melhor a escolha, mais rápido o cérebro irá automatizar o movimento a partir da decisão consciente, sendo esta uma habilidade que o instrumentista desenvolve à medida que vai trabalhando obras ao longo de sua carreira. Dessa forma, esta ferramenta envolve compreensão e movimento, sendo aconselhada sua aplicação em todas as etapas do trabalho, visando ao aprimoramento do controle motor. Complementando, inclui-se aqui o conceito de economia do movimento, onde se busca maior resultado musical com menor esforço físico (KAPLAN, 1987, p.17-18). Segundo Gordon (citado por USZLER et al, 2000, p.309-311), este princípio fora proposta primeiramente por Otto Ortmann em 1929, na sua publicação The Physiological Mechanics of Piano Technique. Porém, pode ser considerado uma extensão da ideia de "relaxamento" (ou flexibilidade) e liberdade de movimento de Rudolf Maria Breithaupt e Tobias Matthay (Gordon, citado por USZLER et al, 2000, p.300). Tais conceitos se contrapõem a vários métodos de ensino do Piano de até então, baseados na aquisição de "independência digital" e "força muscular" através do estudo com aplicação de força e movimentos amplos. Tal concepção é observada no método Klavierschüle, com autoria de Sigmund Lebert e Ludwig Stark, adotado no Conservatório de Stuttgart a partir da segunda metade do século XIX (Bomberger, citado por PARAKILAS, 2001, p.129-130).

Estudo lento: execução de trechos em andamento mais lento do que o indicado ou concebido pelo intérprete. Seu foco é a eficácia do movimento (dissociação, automatização, memória cinestéstica e visual), aprimorando as habilidades motoras através de observação crítica e atenta ${ }^{24}$. Permite um enfoque melhor direcionado da concentração, sendo difícil o controle em fluxos densos ou rápidos de informações, auxiliando assim na assimilação de trechos complexos (BARRY, 1992). Todavia, esta ferramenta não é eficiente em termos de entendimento e fluência musical caso sejam utilizados andamentos muito lentos, não sendo recomendada sua aplicação em casos de dificuldade na compreensão musical e fixação das memórias lógica e auditiva. CHANG alerta que a demanda muscular em andamentos muito mais lentos é diferente, levando ao armazenamento de movimentos que não serão utilizados na performance do andamento desejado (CHANG, 2009, p.20).

Estudo com metrônomo: execução da obra ou trechos com o andamento definido pelo metrônomo. Em princípio, este recurso pode ser utilizado sob duas finalidades: aprimoramento da regularidade rítmica e automatização dos movimentos. No segundo caso, é comum o instrumentista aumentar gradualmente 0 andamento até atingir a fluência desejada no trecho estudado. Porém, é uma ferramenta que traz limitações de ordem musical, uma vez que o metrônomo não permite trabalhar mudanças de agógica. Logo, é necessário ter esta questão em mente, complementando o estudo com ferramentas que possam suprir esta limitação.

Variação: modificação de elementos musicais do trecho estudado. Esta ferramenta permite a aquisição de novas habilidades motoras, além de trabalhar a compreensão musical da peça estudada. Podem ser utilizadas variações ritmicas, de dinâmicas, de tipos de ataque e retrogradações melódicas, entre outras. É uma ferramenta que traz motivação ao processo de estudo, pois exige um trabalho criativo sobre os diversos aspectos 
musicais. Como seu objetivo não é a memorização do trecho musical, os elementos de atividade enfatizados são prioritariamente consciência e movimento, havendo também o desenvolvimento da memória cinestésica para a aquisição de novas habilidades motoras.

Repetição de trechos: execução de um trecho da obra por diversas vezes. É um recurso bastante completo, pois trabalha a compreensão, automatização e memorização, requerendo a análise da peça como referência para a escolha das seções a serem trabalhadas. É uma ferramenta essencial para a prática instrumental segundo KAPLAN (1987, p.76-77), e possui especial importância para consolidação da memória cinestésica, fato reforçado também por pesquisadores da Performance Motora, em pesquisas voltadas a atletas (SCHMIDT e WRISBERG, 2008, p.48). Recomenda-se que os trechos selecionados sejam curtos e, principalmente, dotados de um significado musical ${ }^{25}$, tornando assim o estudo consciente e acelerando o processo de memorização. Uma problemática comum acerca desta ferramenta, apontada por diversos autores, é quando o processo de repetição é realizado de forma desatenta. É fundamental manter a atenção direcionada aos diversos aspectos da prática instrumental: o corpo, a digitação ou dedilhado e a sonoridade, entre outros. Quando a repetição se torna desatenta, o estudo fica apoiado somente nas informações automatizadas, dando uma falsa impressão de segurança e podendo levar a falhas de memória em apresentações públicas (CHANG, 2009, p.38). É a repetição consciente que mantém as informações registradas na memória, conforme reforça COSO (1992, p.24-25).

Repetição da peça: execução da obra na integra por diversas vezes. É utilizada para aquisição de resistência e preparação para a performance na etapa de execução, através de um entendimento amplo do repertório. Para que seja aplicada, é necessário haver segurança e consciência adquirida a partir de outras ferramentas, pois esta requer um nível seguro de automatização, sendo sua utilização exclusiva arriscada e não recomendada. Trabalha em especial a evocação, pois permite consolidar uma visão interpretativa completa do repertório mediante saberes históricos, culturais, estilisticos e pessoais.

Estudo por pontos de referência: trata-se de definir trechos de relevância formal e musical na obra, iniciando a execução a partir deles. Esta ferramenta é de grande auxílio para a manutenção da memória, sendo utilizada com maior eficiência na etapa de execução. A escolha dos pontos de referência se dá através da consciência, sendo definidas por seções da peça que possuam sentido musical, assim como no estudo de repetição. CHAFFIN reforça a importância de reconhecer seções de uma peça para sua memorização, além da utilização de conhecimentos históricos sobre forma musical (CHAFFIN et al, 2002, p.71), representados pela "evocação" no método apresentado. Assim, é recomendado para reforço e manutenção da memória na performance.
Apresentação para grupo restrito: performance do repertório para um pequeno grupo de pessoas, caracterizando uma situação de pouca exposição pública. $\mathrm{Na}$ etapa de execução, apresentar o repertório para um número reduzido de pessoas é um recurso eficaz para atenuar a tensão no momento da performance, aumentando a segurança e auto-confiança do instrumentista. Além disso, pode apontar eventuais falhas de memória não perceptíveis no estudo individual, indicando trechos que precisam ser mais estudados.

Guias de execução ${ }^{26}$ : são elementos musicais utilizados como referência para a prática instrumental, escolhidos de acordo com seu significado para cada instrumentista ao longo da obra, visando à sua automatização (CHAFFIN et $a l, 2002$, p.71). Tais elementos podem ser uma digitação, um acorde, realização de um crescendo, tipo de toque ou até uma inflexão agógica, sendo inúmeras as combinações possiveis de guias em uma determinada obra musical, variando para cada intérprete. Esta ferramenta parte do pressuposto que o foco da concentração enfatiza aspectos musicais variados ao longo da obra, devendo ser estes os guias para memorização e execução. CHAFFIN afirma que o objetivo do intérprete deve ser as realizações expressivas, e não os problemas da execução (CHAFFIN et al, 2002, p.72). Logo, esta ferramenta enfatiza o entendimento musical, reforçando a memória lógica e auditiva, porém, não favorece o aprimoramento da memória cinestésica, além de exigir um nível satisfatório de habilidades motoras previamente assimiladas.

Ensaio mental: estudo internalizado da peça, sem a realização física de sua performance. Vários trabalhos acadêmicos tem investigado a eficácia desta ferramenta, especialmente porque envolve ação exclusiva da consciência para a preparação do repertório, exigindo uma imagem pré-concebida da obra, evocação de habilidades motoras internalizadas e uso eficiente do tempo, enfatizando assim um estudo objetivo e não a prática deliberada. Segundo Barry e Hallam (citadas por PARNCUTT e MCPHERSON, 2002, p.153-143), esta ferramenta contribui para consolidar um comportamento atento durante a prática, porém, é mais eficaz se 0 executante já possuir familiaridade com o repertório e as habilidades motores necessárias para sua execução, não sendo recomendado a iniciantes.

4.2 Ferramentas Idiomáticas: constituem as técnicas de estudo de um instrumento musical em particular. Aqui, seguem-se alguns exemplos para ilustração:

Estudo de mãos separadas (Piano): executar um sistema ou notação direcionada a uma mão apenas, revezando o mesmo procedimento com outra mão. Na etapa de estudo, permite conhecer e entender musicalmente a obra, além de permitir sua assimilação motora. Em passagens complexas ou de difícil domínio por parte do executante, a repetição de trechos aliada ao estudo de mãos separadas mostra-se extremamente eficaz no 
processo de aprendizado, podendo se concentrar no aprimoramento das habilidades motoras (CHANG, 2009, p.31-32). Na etapa de execução, esta ferramenta ajuda na manutenção das memórias cinestésica e auditiva, além de favorecer a descoberta de novas interpretações para certos elementos musicais, sendo um instrumento essencial à prática pianística.

Estudo sem pedal (Piano): consiste na execução de um trecho que era usualmente realizado com o pedal, de acordo com a interpretação do pianista. Este estudo permite trabalhar o movimento graças à carência das ressonâncias do pedal, devendo o instrumentista reagir à sonoridade apenas com os dedos e, por exemplo, sustentar mais as passagens em legato. Tal estudo é fundamental para a performance segundo CHANG (2009, p.51-52), pois o pianista não fica tão dependente do pedal para conseguir a sonoridade desejada, preparando-o para lidar com os diversos tipos de piano e acústica das salas de concerto, um problema específico deste instrumento.

Estudo da mão esquerda (Violão): baseia-se na execução de um trecho ou de toda a obra, utilizando apenas a mão esquerda. Nesse estudo, enquanto o braço direito permanece relaxado, a mão esquerda ataca as cordas do instrumento para que as notas possam soar, mesmo não sendo na sonoridade desejada. Essa ferramenta é essencial para desenvolver a memória cinestésica da mão esquerda, favorecendo a independência entre as mãos. Logo, se houver um pequeno equívoco no dedilhado da mão direita durante a performance, a mão esquerda pode providenciar uma certa autonomia no movimento. Assim sendo, o estudo em questão visa ao trabalho do movimento e da memória, e deve ser complementado com um estudo que contemple a consciência musical.

\section{Fatores que influenciam a prática instrumental}

Além dos elementos já descritos, há diversos fatores que influenciam o processo de aprendizagem e prática da Performance Musical que não estão presentes no modelo exposto anteriormente. É necessário que o instrumentista esteja ciente destas questões, evitando eventuais problemas na preparação ou na performance. A seguir, há uma exposição destes fatores:

5.1 Motivação: realçando o que fora exposto, KAPLAN afirma que a motivação é um elemento fundamental para a prática instrumental, pois devido à alta demanda prática necessária para a aprendizagem da Performance Musical, o executante precisa de objetivos concretos que o motivem a realizar um estudo sólido e aprofundado. Entretanto, conforme dito anteriormente, o ensino tradicional de Música não considera este aspecto, levando os alunos à desmotivação e subsequente evasão da prática musical (VIEGAS, 2006, p.5). Uma estratégia seria flexibilizar a escolha do material didático (repertório), devendo este se adequar ao patamar de desenvolvimento instrumental do aluno. Outra possibilidade é suscitar a curiosidade do estudante, oferecendo-Ihe informações sobre a relevância histórica da peça, personalidade do compositor, reforçar aspectos musicais e estruturais da peça, sugerir uma imagem para a sonoridade que se deseja obter, entre outros (KAPLAN, 1987, p.64). Ainda, O'Neill e McPherson (citados por PARNCUTT e MCPHERSON, 2002, p.31-46) reforçam a importância de desenvolver a autocrítica do executante, utilizando estratégias de ensino que lhe permitam avaliar seu rendimento de forma equilibrada. Por último, os autores reforçam a adoção de metas que o executante pode atingir, organizando assim o processo de aprendizagem.

Outro fator importante para a motivação é a escolha das ferramentas de estudo adequadas. 0 trabalho do instrumentista concentra-se em um contato rotineiro com o instrumento, sendo assim, as ferramentas que providenciam maior interesse musical tendem a ser mais motivadoras do que as concentradas em outros aspectos da prática instrumental, como a questão mecânica dos dedilhados, por exemplo.

5.2 Concentração: também denominada atenção, os processos que envolvem esta atitude tem sido objeto de estudo da neurociência e da psicologia cognitiva. Estudos recentes (HOMMEL et al, 2002, p.215-219) apontam que o controle cognitivo (manipulação mental das informações) origina-se a partir de dois mecanismos: atitudes automáticas (tendências, hábitos ${ }^{27}$ ) ou processos controlados (ação consciente), podendo ser influenciado por duas fontes: internas (objetivos, consciência da ação) e externas (percepção e estímulos), atuando de forma simultânea e interrelacionada ${ }^{28}$. Assim, a concentração é o enfoque mental dado a informações processadas em um momento, seja através da percepção de um estímulo ou da escolha de uma ação apropriada.

Transpondo esta ideia para a Música, a concentração representa o enfoque do executante em uma determinada atividade, estando presente em todas as etapas da prática instrumental. Ainda, é possivel desenvolvê-la, pois à medida que se cria o hábito de estudar, o tempo e a eficácia da concentração aumentam, demonstrando ser uma habilidade que permite aprimoramento. Pesquisas da área de Neurociência - como as de ALTENMÜLLER (2007) e WATSON (2009) - reforçam que o cérebro de músicos possui maior "plasticidade", possuindo determinadas áreas mais desenvolvidas do que em indivíduos nãomúsicos, especialmente no que diz respeito ao mecanismo sensorial. Tal fato indica que o estudo da Música requer um desenvolvimento fisiológico particular, reforçando que para adquirir saberes e habilidades de forma integrada, é preciso tempo para a devida adaptação do cérebro.

Outro fato relevante é a função desempenhada pela concentração em cada fase da preparação. Na etapa de estudo, a concentração é fundamental para que os elementos de atividade sejam consolidados. Por muitas vezes, a demanda de informações são complexas, devendo o instrumentista usufruir das ferramentas de estudo para sua simplificação, e assim usufruir da concentração de 
forma eficiente no processo de assimilação do conteúdo ${ }^{29}$. $\mathrm{KOCH}$ e TSUCHIYA comentam esta necessidade:

\begin{abstract}
Organismos complexos e cérebros costumam sofrer por excesso de informações. (...) Uma forma de lidar com esta questão é selecionar uma pequena fração e processar este input reduzido em tempo real, enquanto a porção não atenta do input é processada a uma taxa de transferência reduzida. (KOCH e TSUCHIYA, 2006, p.16)
\end{abstract}

Complementando, SCHMIDT e WRISBERG (2008, p.4446) reforçam que o ser humano é capaz de realizar somente duas atividades simultâneas, sendo aquela que está sob o foco de atenção a atividade dominante. A secundária, por sua vez, não permite um controle mais amplo. Sendo assim, é evidente a necessidade de um bom direcionamento da concentração durante a prática, tendo em vista esta limitação fisiológica.

A seguir, na etapa de execução, é necessário um enfoque atento ao fluxo musical e à sonoridade. Sendo assim, a postura do executante durante o estudo se aproxima à requerida no momento da performance. É comum que a concentração varie durante o estudo, mesmo sem haver erros na execução devido à automatização dos movimentos e da memória lógica, sendo este um ponto delicado na prática instrumental devido à dependência da memória. Altman comenta este problema:

Neste trabalho, o controle baseia-se em armazenar uma tarefa na memória ativa. Assim que ela é arquivada, o impacto ativo do processo de controle é interrompido, sendo o sucesso ou falha no desempenho de tal tarefa uma função direta do esquecimento, ainda, dos atributos dos processos nos quais o controle foi delegado. (Altman, citado por HOMMEL et al, 2002, p.216)

Esta questão ocorre justamente porque durante 0 estudo, a concentração não está voltada à manutenção do movimento e da memória, podendo haver perdas no armazenamento das informações. Infelizmente, o estudo individual do instrumento pode não transparecer tais falhas, vindo a surgir apenas durante as apresentações públicas. Logo, é fundamental que o executante esteja atento a questão, utilizando ferramentas de estudo que permitam manter as informações registradas na memória, providenciando assim um patamar de segurança para a performance.

5.3 Intuição: por ser um conceito comumente associado ao inexplicável, incrédulo e emocional, a intuição é uma forma de conhecimento desvalorizada sob o âmbito acadêmico e educacional (BRUNER, 1960, p.56), em contraponto à razão. Assim, a intuição está associada a experiências subjetivas e ao aprendizado implícito, portanto, não segue a estrutura lógica do pensamento analítico, onde se tem a consciência dos fatores positivos e negativos de uma decisão fundamentada. Mesmo assim, é possivel determinar um campo de prováveis decisões, onde pode emergir uma atitude intuitiva (LIEBERMAN, 2000, p.109-111). É possivel ainda associar o caráter nãoverbal da linguagem musical com a transmissão implícita de conhecimentos, reforçando sua importância para a prática instrumental.
Para sua inserção neste modelo, a intuição deve ser compreendida como uma tomada de decisões musicais e interpretativas com base nas experiências musicais e culturais do instrumentista, sendo estas as delimitadoras do campo de prováveis decisões. Assim sendo, envolve a formação musical do intérprete, ideias de músicos que são sua referência, conhecimentos adquiridos através de professores, caracteristicas do estilo musical, questões históricas acerca da peça e imagem da personalidade do compositor, entre outros. Reforçando tal ponto de vista, a intuição pode ser considerada o diálogo entre identidade (propriedades do indivíduo) e cultura (propriedades da sociedade), delineando assim a interpretação musical. Por fim, as decisões intuitivas são objetivamente representadas através da performance, sendo este o meio de expressão das ideias musicais. É onde o instrumentista realiza o seu diálogo com a obra, o compositor, a sociedade e a cultura.

5.4 Técnica: este é um dos objetivos paralelos do ensino da Performance Musical. Portanto, ter claro em mente o conceito de técnica permite delinear de forma mais objetiva todo o processo de estudo e escolha do repertório. Por muito tempo, acreditava-se - e esta ideia ainda perdura - que a técnica fosse um processo relativo às ações fisiológicas: força muscular, velocidade dos movimentos e independência motora, entre outras denominações, que segundo KAPLAN (1987, p.31), isto ocorre porque o controle motor é muito aparente. Dessa forma, Kaplan apresenta uma conceituação de que técnica envolve a coordenação dos movimentos corporais, ou seja: é um processo psicológico, que envolve mais o desenvolvimento do controle motor do que a velocidade dos movimentos em si. Dessa forma, o executante deve direcionar sua prática para o desenvolvimento do controle motor, buscando conforme dito anteriormente - maior resultado musical com o menor esforço físico (KAPLAN, 1987, p.17-18).

Ainda, o presente modelo permite propor uma conceituação mais ampla de técnica (CEROUEIRA, 2011, p.16). Sabendo que a Performance Musical envolve consciência corporal (movimento), memória (aquisição/ automatização) e consciência (conhecimento musical), é possivel assumir que o conhecimento de História da Música faz parte da técnica, pois ele influencia diretamente a interpretação da obra, fato refletido em como o executante estudará a peça a partir da sonoridade pretendida. Esta concepção explica porque músicos com grande domínio de habilidades motoras não interpretam com sucesso obras em estilos que não possuem familiaridade, fazendo com que o próprio conhecimento de estilos musicais - que envolve imagem sonora, intuição, saberes lógicos de forma, harmonia e fraseologia, entre outros - seja necessariamente parte da técnica. Esta concepção se relaciona com o estudo de escalas e arpejos ainda exigidos em grande parte das instituições de ensino musical, pois nesta situação, partese do pressuposto de que a aquisição de habilidades motoras por si só bastam para a consolidação da técnica. 
Vícios Motores: termo utilizado por KAPLAN (1987, p.9294) para se referir à aquisição - ou automatização - de movimentos com alto grau de ativação muscular, que poderiam ser mais adequados se adquiridos através de um estudo consciente e com menor grau de esforço. Esta é uma das maiores problemáticas da prática instrumental, que em situações mais graves, pode levar à fadiga muscular, tendinite e até à lesão por esforço repetitivo. Neste caso, a solução é realizar uma reeducação corporal ao instrumento, trabalhando o armazenamento de movimentos mais adequados, substituindo os antigos. Diversos métodos baseados na aquisição de força muscular e independência motora levaram gerações de executantes a adquirir tais enfermidades, fato que levou Rudolf Maria Breithaupt - um dos pioneiros no conceito de "relaxamento" - a auxiliar pianistas com problemas de tensão muscular no início do século XX (Gordon, citado por USZLER et al, 2000, p.298). Daí a preocupação em adotar estratégias de estudo conscientes e saudáveis.

Outra questão semelhante remete a músicos que trabalham em ambientes de grande pressão psicológica, como em orquestras ou preparação para exames de performance, por exemplo. Durante a prática, é possível que o executante não esteja em pleno "relaxamento" maior nível de desativação muscular - levando-o a adquirir movimentos inadequados. Ainda, mesmo executantes que possuam habilidades motoras eficientes podem sofrer com a pressão psicológica, levando-os a perder 0 controle sobre a musculatura. Neste caso, não há danos fisiológicos aparentes, sendo um problema provindo de alterações no metabolismo do sistema nervoso (Gerloff e Hummel, citados por ALTENMÜLLER et al, 2006, p.239), alterando o rendimento da Performance Musical em contextos onde há alta demanda de informações. Esta enfermidade é conhecida como Distonia Focal, sendo objeto de diversas investigações na área de Neurociência. Neste caso, é importante procurar por orientações médicas na especialidade de Neurologia, sendo muito importante evitar ambientes com alto nivel de pressão psicológica. Por fim, Brandfronbrener e Kjelland (citados por PARNCUTT e MCPHERSON, 2002, p.83) reforçam que os problemas ocupacionais enfrentadas pelos músicos provém de pressão psicológica e subsequente reflexo no nível de tensão muscular, cabendo à Medicina do Músico - área que trata de doenças oriundas desta profissão trabalhar de forma colaborativa com a Educação Musical.

5.5 Ansiedade na Performance: esta questão é conhecida de diversos músicos quando sobem ao palco, sendo objeto de diversas pesquisas no meio acadêmico. Segundo WILSON e ROLAND (2002, p.47), a ansiedade atinge músicos em situações de exposição pública ou competição, e conforme dito anteriormente, atletas em condições semelhantes, comprometendo seu controle motor (SCHMIDT; WRISBERG, 2008, p.56). Segundo Jørgensen (citado por WILLIAMON, 2004, p.95) e Kesselring (citado por ALTENMÜLLER et al, 2006, p.309-310), pode haver falhas de memória, comportamentos motores expressivos como tremuras e necessidades fisiológicas, reações do sistema nervoso autônomo como suor e palpitação, e sentimentos subjetivos que alteram significativamente a percepção da realidade e a autocrítica, entre outros. Um nivel controlado de tensão pode ser favorável à performance, pois aumenta a concentração e favorece 0 fluxo musical. Porém, se houver constantes pensamentos negativos, baixa autoconfiança ou sensações de pânico, 0 resultado pode ser inverso. Ainda, é observado o aumento da adrenalina na corrente sanguínea, que tem a função de preparar o corpo para uma situação de risco.

Algumas estratégias de origem psicológica dizem respeito a desenvolver expectativas realísticas quanto à performance, evitando pensamentos de cobrança e baixa auto-estima. Ainda, KIRCHNER (2005, p.31) reforça posturas psicológicas no momento da apresentação, como focar no presente (não pensar em passagens difíceis que virão), evitar diálogo interno (atrapalha a concentração) e não ter pensamentos negativos, entre outros. Kesselring (citado por ALTENMÜLLER et al, 2006, p.314) menciona a importância de se manter uma alimentação equilibrada, para que o corpo mantenha um fluxo constante de energia. Com relação a ferramentas de estudo, Kirchner sugere estudar por pontos de referência, gravar uma performance para análise crítica e ensaiar o repertório antes da apresentação pública. CARDASSI (2000, p.251-257) acrescenta atentar a questões não musicais do concerto, como divulgação, distribuição de programas e trajes a se vestir, entre outros. Além destes procedimentos, formas externas ao controle individual podem ser utilizadas, como técnicas para melhor aproveitamento da musculatura (respiração profunda, Yoga ou técnica de Alexander, por exemplo) e até mesmo o uso de tranqüilizantes e beta-bloqueadores antes da performance, sendo estes últimos controversos devido à necessidade de acompanhamento médico (Kesselring, citado por ALTENMÜLLER et al, 2006, p.314-315).

\section{Exemplos de aplicações práticas do Modelo} A seguir, apontamos alguns dos problemas apresentados por instrumentistas, ilustrando-os com possiveis sugestões baseadas no Modelo de Ensino e Aprendizagem da Performance Musical:

A "técnica instrumental" apresenta-se muito bem trabalhada, mas o executante tem pouca expressividade: é um problema provindo da consciência, por tratar-se de uma carência de entendimento musical. A musicalidade deve estar desenvolvida, e para isto, o executante pode ouvir interpretações de artistas importantes, percebendo a condução das frases, harmonias, tipos de toque, agógica e outros elementos do discurso musical presentes. Em seu estudo, recomenda-se utilizar ferramentas que favoreçam trabalhar questões musicais, como variação, repetição de trechos, repetição da peça e estudo por pontos de referência. 
Durante uma apresentação, houve um "branco" em um trecho que parecia estar seguro: trata-se de um problema relacionado à memória, sendo este "branco" característico de falha nas memórias de movimento e consciência simultaneamente. Sendo assim, é provável que o executante não estivesse utilizando ferramentas que não favoreciam a manutenção das informações. Assim, recomenda-se aplicar análise de dedilhados e estudo lento para reforço da memória cinestésica e visual, e repetição de trechos e estudo por pontos de referência para manter a memória lógica e auditiva, sendo estas duas últimas úteis também para as memórias de movimento.

\section{Considerações Finais}

Desde o surgimento dos instrumentos musicais até os dias de hoje, a transmissão de conhecimentos relativos à execução usufruiu de metodologias pedagógicas diversas, caminhando paralelamente às conjunturas histórico-culturais. Os primeiros instrumentos musicais da cultura Ocidental provavelmente eram aprendidos através da percepção e observação, assim como na atual música popular, porém, logicamente desprovidos do aparato tecnológico e de registros sonoros presente na atualidade. Além disso, havia aulas de instrumento cujo repasse de informações se dava através da relação mestre e aprendiz, conforme analogia estabelecida por HARNONCOURT (1988, p.29).

A institucionalização do ensino musical surgiu não apenas como ferramenta para o ensino de instrumentos musicais, mas como uma forma de trazer a esta necessidades histórico-culturais que se apresentavam, inserindo o saber musical na academia. Tal realização foi importante para que a prática musical acompanhasse as inovações tecnológicas e filosóficas de seu tempo, seguindo o percurso histórico.

No século $X X$, o desenrolar dos acontecimentos históricos aconteceu em grande velocidade, porém, a pedagogia dos instrumentos musicais não foi capaz de acompanhar tal processo, por uma série de fatores. Um deles é o caráter conservador presente nas instituições de ensino, com idealizações românticas do que seria o perfil ideal de um músico: o concertista solista ${ }^{30}$. Esta hierarquia de valorações sociais continua disseminada na academia, sendo um fator de resistência aos ideais presentes em um mundo que se encontra em constante mutação, sendo o grande prejuizo traduzido na formação de alunos à margem da realidade. Assim sendo, a pesquisa realizada em diversas áreas do conhecimento não obteve sua inserção no processo de ensino instrumental de forma efetiva, ao contrário do que ocorreu com os "métodos ativos".

Sob esta perspectiva, espera-se que o modelo e as considerações presentes neste artigo, somada a outros importantes trabalhos da pedagogia dos instrumentos musicais, possa fornecer à prática instrumental ferramentas necessárias a um planejamento consciente e objetivo do ensino de instrumentos musicais. Assim sendo, o modelo apresentado pode se mostrar um eficiente auxílio para a prática instrumental, refletindo sobre pressupostos tradicionais de ensino sem perder a essência da produção artística. Para isto, reconhecemos a qualidade intrínseca da Arte como forma de saber paralela à razão, bem como seu espaço nas instituições acadêmicas, tradicionais defensoras do saber científico.

\section{Referências}

ALTENMÜLLER, Eckart. From the Neanderthal to the concert hall: Development of sensory motor skills and brain plasticity in music performance. In: International Symposium on Performance Science, Porto, 2007.

BARRY, Nancy H. The Effects of Practice Strategies, Individual Differences in Cognitive Style, and Gender upon Technical Accuracy and Musicality of Student Instrumental Performance. In: Psychologyof Music, v. 20, n² 2, 1992, p.112-123.

BARRY, Nancy H; HALLAM, Susan. Practice. In: PARNCUTT, Richard; MCPHERSON, Gary. The Science \& Psichology of Music Performance: Creative Strategies for Teaching and Learning. Oxford University Press, Nova York, 2002. p.151-166

BERIO, Luciano. Entrevista sobre a Música Contemporânea (realizada por Rosana Dalmonte). Ed. Civilização Brasileira, Rio de Janeiro, 1988.

BRANDFONBRENER, Alice G; KJELLAND, James M. Music Medicine. In: PARNCUT, Richard; MCPHERSON, Gary. The Science \& Psichology of Music Performance: Creative Strategies for Teaching and Learning. Oxford University Press, Nova York, 2002. p.82-96

BRASIL. Lei $n^{\circ} 11.769 / 08$ de 19 de agosto de 2008.

BRUNER, Jerome Seymour. The Process of Education. Harvard University Press, Cambridge, 1960.

CARDASSI, Luciane. Pisando no Palco: prática de performance e produção de recitais. In: Anais do I Seminário Nacional de Pesquisa em Performance Musical. Belo Horizonte: UFMG, 2000, p.251-257.

CERQUEIRA, Daniel Lemos. Compêndio de Pedagogia da Performance Musical. Edição do Autor, São Luís, 2011. Disponível em http://musica.ufma.br. 
CHAFFIN, Roger; IMREH, Gabriela; CRAWFORD; Mary. Practicing Perfection: Memory and Piano Performance. Lawrence Erlbaum Associates Publishers, Mahwah, 2002.

COSO, Jose Antonio. Tocar un instrumento: Metodologia del Estudio, Psicología y Experiencia Educativa en el Aprendizaje Instrumental. Editorial Música Mundana, Madri, 1992.

ESPERIDIÃO, Neide. Educação profissional: reflexões sobre o currículo e a prática pedagógica dos conservatórios. Revista da $A B E M, n^{0} 7$, set-2002. Porto Alegre, 2002, p.69-74.

FISHER, Christopher. Teaching Piano in Groups. Oxford University Press, Nova York, 2010.

FONTERRADA, Marisa Trench de Oliveira. De Tramas e Fios: um ensaio sobre Música e Educação. Ed. UNESP, São Paulo, 2005. $1^{\text {a }}$ ed

FUCCI AMATO, Rita de Cássia. Educação pianística: o rigor pedagógico dos conservatórios. Música Hodie, v. 6, n 1 . Goiânia: UFG, 2006, p.75-96.

da ANPPOM, São Paulo, 2007.

O Piano no Brasil: uma perspectiva histórico-sociológica. In: Anais do XVII Congresso

GERLOFF, Christian; HUMMEL, Friedhelm. The role of inhibition in the motor control of finger function. In: ALTENMÜLLER, Eckart; WIESENDANGER, Mario, KESSELRING, Jürg. Music, Motor Control and the Brain. Oxford University Press, Nova York, 2006. p.239-247

GINSBORG, Jane. Strategies for Memorizing Music. In: WILLIAMON, Aaron (org.). Musical Excellence: Strategies and techniques to enhance performance. Oxford University Press, Nova York, 2004. p.123-141

GLASER, Scheila. Criatividade na aula de piano: múltiplas facetas. Revista A, v. 1, mar-2007. UNESP: São Paulo, 2007. Disponível em meio digital.

GLASER, Scheila; FONTERRADA, Marisa. Músico-Professor: uma questão complexa. Música Hodie, v. 7, $n^{0}$ 1. Goiânia: UFG, 2007, p.27-49.

GORDON, Stewart. Etudes for Piano Teachers. Oxford University Press, Nova York, 1995.

HARNONCOURT, Nikolaus. O Discurso dos Sons: Caminhos para uma nova compreensão musical.Ed. Jorge Zahar, Rio de Janeiro, 1988.

HOMMEL, Bernard; RIDDERINKHOF, Richard; THEEUWES, Jan. Cognitive control of attention and action: issues and trends. In: Psychological Research, 2002, v. 66, p.215-129.

HUDSON, Glenn; ROLAND, David. Performance Anxiety. In: PARNCUT, Richard; MCPHERSON, Gary. The Science \& Psichology of Music Performance: Creative Strategies for Teaching and Learning. Oxford University Press, Nova York, 2002. p.47-61

JØRGENSEN, Harald. Strategies for Individual Performance. In: WILLIAMON, Aaron (org.). Musical Excellence: Strategies and techniques to enhance performance. Oxford University Press, Nova York, 2004. p.85-103

KAPLAN, José Alberto. Teoria da Aprendizagem Pianística. Ed. Movimento, Porto Alegre, 1987. $2^{\text {a }}$ ed

KESSELRING, Jürg. Music performance anxiety. In: ALTENMÜLLER, Eckart; WIESENDANGER, Mario, KESSELRING, Jürg. Music, Motor Control and the Brain. Oxford University Press, Nova York, 2006. p.309-318

KIHLSTROM, John. The cognitive unconscious. Science Magazine, v. 237, p.1445-1452.

KIRCHNER, Joann. Managing musical performance anxiety. American Music Teacher, dec-2005, p.31-33.

KOCH, Christof; TSUCHIYA, Naotsugu. Attention and counsciouness: two distinct brain processes. TRENDS in Cognitive Sciences, nov-2006, v. 11, n 1, p.16-22.

KOVACS, Sandor. Untersuchungenüber das musikalische Gedächtnis. Zeitschriftfürangewandte Psychologie, v. 11, p.113135.

KRAMPE, Ralf T; ERICSSON, K. Anders. Deliberate practice and elite musical performance. In: RINK, John (org.). The Practice of Performance: studies in musical interpretation. Cambridge University Press, Cambridge, 1995. p.84-102

LAWSON, Colin James; STOWELL, Robin. The historical performance of music: an introduction. Cambridge University Press, Cambridge, 1999.

LESTER, Joel. Performance and analysis: interaction and interpretation. In: RINK, John (org.). The Practice of Performance: studies in musical interpretation. Cambridge University Press, Cambridge, 1995. p.197-216

LIEBERMAN, Matthew. Intuition: A Social Cognitive Neuroscience Approach. PsychologicalBulletin, 2000, v. 126, n 1, p.109-137.

O'NEILL, Susan A; MCPHERSON, Gary E. Motivation. In: PARNCUTT, Richard; MCPHERSON, Gary. The Science \& Psichology of Music Performance: Creative Strategies for Teaching and Learning. Oxford University Press, Nova York, 2002. p.31-46

PARAKILAS, James (org). Piano Roles: three hundred years of life with the Piano. Yale University Press, New Haven, 2001.

PÓVOAS, Maria Bernardete Castelán; SILVA, Daniel da; PONTES, Vânia Éger. Ação Pianística e Coordenação Motora redução do movimento como possibilidade de otimização da técnica com foco na transmissão do conteúdo musical.In: Anais do XVIII Congresso da ANPPOM, Salvador, 2008. p.329-333

RUGIU, Antônio Santoni. Nostalgia do Mestre Artesão. Ed. Autores Associados, Campinas, 1998. 
SCHMIDT, Richard, A; WRISBERG, Craig A. Motor Learning and Performance. Human Kinetics, Champaign, 2008. $4^{a}$ ed SPRENGER, Marilee. Learning \& Memory: the brain in action. Association for Supervision and Curriculum Development, Alexandria, 1999.

SUZUKI, Shinichi. Shinichi Suzuki: His Speechs and Essays.Warner Bros Publications, Miami, 1998.

USZLER, Marienne; GORDON, Stewart; SMITH, Scott McBryde. The Well-Tempered Keyboard Teacher. Schirmer Books, Nova York, 2000. $2^{\text {a }}$ ed

VIEGAS, Maria Amélia de Resende. O ensino de Piano no Curso Técnico do Conservatório Estadual de Música Padre José Maria Xavier de São João del-Rei enquanto Prática Pedagógica Institucional: 0 problema, suas implicações, e perspectivas. Cadernos do Colóquio. Rio de Janeiro: UNIRIO, 2006.

WATSON, Alan H. D. The Biology of Musical Performance and Performance-Related Injury. Scarecrow Press Inc, Toronto, 2009.

\section{Notas}

1 No Brasil, a primeira instituição foi criada em 1841 por Francisco Manuel da Silva, o Imperial Conservatório, atual Escola de Música da UFRJ. (ESPIRIDIÃO, 2006, p.85)

2 Infelizmente, o piano é frequentemente associado ao modelo de ensino tecnicista, sendo uma razão o status dado ao estudo deste instrumento nos conservatórios (FUCCI AMATO, 2007, p.93), além de sua ampla presença no repertório europeu Ocidental.

3 Esta era a abordagem adotada no Conservatório Dramático e Musical de São Paulo e no Conservatório Musical de São Carlos (FUCCI AMATO, 2006, p.75), assim como nos conservatórios mineiros, diferindo apenas no periodo de sua fundação (ESPIRIDIÃ0, 2006, p.86).

4 "(...) pode-se dizer que, quando um aluno trabalha por mera repetição, obediência, memorização e submissão, dentro de uma situação que é fruto de conformismo em relação a um estímulo controlador, ele não está sendo criativo, mesmo que esteja participando de atividades criadoras." (GLASER, 2007, p.3)

5 Tal tipo de estudo é criticado por Kaplan e será comentado adiante.

6 Este termo ficou conhecido por referir-se às novas propostas e abordagens da Educação Musical. A questão que se discute é que alguns de seus autores não elaboraram métodos de ensino propriamente, mas ideias e pressupostos nos quais basearam suas práticas docentes.

7 Esta abordagem metodológica pode trazer sérias consequências para o aluno, uma vez que exime-o de vivenciar seu contexto social e histórico.

80 aspecto mais controverso é saber que o indivíduo é fruto de seu meio, mas o "seu meio" encontra-se manipulado e artificializado, criando uma falsa sensação de liberdade.

9 Kaplan reforça que ainda há professores de instrumento que acreditam em talento, selecionando e marginalizando alunos sob tal pretexto: "(...) o homem não é um ser especializado, e que, portanto, não há comportamento que seja capaz de adquirir, devidamente orientado. 0 ser humano não tem aptidões, tem potencialidades!" (KAPLAN, 1987, p.12)

10 Na pedagogia tradicional do piano, é comum ouvir frases do tipo "fulano está velho para aprender" ou "ciclano não é talentoso". Tais afirmações, além de desrespeitosas, são extremamente desmotivadoras.

11 A otimização dos movimentos para a prática instrumental tem sido objeto de pesquisas interdisciplinares, em especial no piano (PÓVOAS; SILVA; PONTES, 2008, p.329)

12 Uma ideia constantemente presente na Música é o equilíbrio. Existem instrumentistas e obras que supervalorizam a habilidade motora, sendo este desequilibrio frequentemente atribuído ao conceito de virtuosismo, infelizmente. Provavelmente o modelo tecnicista de ensino contribuiu para a disseminação desta concepção.

13 Apesar disso, a visão sobre o aprendizado presente nesta teoria baseia-se na imagem musical do intérprete sobre a obra, independentemente do meio de aquisição (através de partitura ou "tirada de ouvido"). Este é principal o motivo pelo qual a memória visual foi considerada um utensilio para a memória cinestésica, ao invés de apenas "fixar a imagem da partitura" (KAPLAN, 1987, p.69).

14 A improvisação é um processo complexo que requer concentração do instrumentista a nível de estruturação musical (Berio, citado por DALMONTE, 1988, p.72), podendo intervir no estudo das habilidades motoras. Daí, faz-se necessário o uso da memória, partindo de uma peça cujo objetivo é "tocar sempre as mesmas notas".

15 KOVACS, pianista húngaro, foi pioneiro nas pesquisas empíricas sobre memorização instrumental, concluindo que seus alunos deveriam estudar entendendo obra, e não focando apenas na sua realização motora (KOVACS, 1916).

16 Definição segundo KAPLAN: "conjunto de funções do psiquismo que nos permite conservar o que foi, de algum modo, vivenciado." (KAPLAN, 1987, p.69)

17 Pesquisadores da cognição sugerem que o instrumentista faça "ensaios mentais" - rehersals - da obra, isto é, imaginá-la sem utilizar movimentos (BARRY, 1992).

18 A esta, também pode ser referida como memória motora.

19 KAPLAN considera que a memória visual ajuda a fixar a imagem da partitura (1987, p.69), porém, nesta teoria, a memória em questão é entendida como elemento que favorece a fixação da memória cinestésica.

20 Chaffin se refere a este elemento como memória analitica (CHAFFIN et al, 2002, p.71)

21 Um termo que é comumente associado a este conceito é "condicionamento".

22 Devido à retenção das informações de movimento, KIHLSTROM qualificou a memória cinestésica como "inconsciente" (KIHLSTROM, 1987)

23 É importante reforçar que novas ferramentas poderão ser adicionadas, enfocando seus objetivos e os elementos trabalhados.

24 Em contrapartida, Jørgensen afirma que o estudo lento não favorece o desenvolvimento das respostas musculares "corretas", pois requer um tipo de demanda muscular diferente do tempo mais rápido (Jørgensen, citado por WILLIAMON, 2004, p.94). 
ørgensen reforça esta ideia, acrescentando que o instrumentista deve ter em mente o significado do trecho em relação à totalidade da peça (JøRGENSEN In: WILLIAMON, 2004, p.93).

26 Alguns autores referem-se a esta ferramenta a partir do termo original em inglês, que é "performance cues".

27 Conceito ligado à automatização, presente no modelo desta teoria.

28 Estes conceitos remetem aos sistemas de input e output presentes na Teoria da Aprendizagem Pianística (KAPLAN, 1987, p.21-24)

29 "Organismos complexos e cérebros costumam sofrer por excesso de informações. (...) Uma forma de lidar com esta questão é selecionar uma pequena fração e processar este input reduzido em tempo real, enquanto a porção não atenta do input é processada a uma taxa de transferência reduzida." (KOCH et al, 2006, p.16)

30 Segundo Gordon, mais de 95\% dos músicos profissionais da atualidade irão dedicar-se a lecionar em algum momento de suas carreiras. Ainda, o autor critica a visão presente nas instituições de ensino musical, que distinguem o educador do instrumentista (GORDON, 1995, p.3-4).

Daniel Lemos Cerqueira é técnico em Piano pela Academia de Música Lorenzo Fernandez na classe da pianista Maria Luísa Urquiza Lundberg, Bacharel em Piano pela Universidade Federal de Minas Gerais (UFMG) na classe do pianista Miguel Rosselini, e Mestre em Performance pela mesma instituição, orientado pela profa. Dra. Ana Cláudia de Assis e sendo aluno de Piano do prof. Dr. Maurício Veloso.Apresentou-se em diversas salas de concerto do Brasil como pianista solista e acompanhador. Participou de festivais e cursos de interpretação com Celina Szrvinsk, Luís Senise, Fany Solter, Michael Uhde, Ricardo Castro e Fernando Corvisier, entre outros, sendo laureado em concursos de interpretação pianística. Foi professor substituto de Piano na Universidade Estadual do Maranhão (UEMA), trabalhando atualmente como professor Assistente na Universidade Federal do Maranhão (UFMA), dedicando-se à docência e pesquisa em Piano e principalmente na área de Ensino da Performance Musical, com 18 publicações em livros, periódicos e eventos nacionais e internacionais. Participou de trabalhos que poderão contribuir ao desenvolvimento da Educação Musical no Maranhão, destacando-se a reforma do Projeto Político-Pedagógico da Escola de Música do Estado do Maranhão (EMEM), principal instituição de ensino musical deste Estado.

Ricieri Carlini Zorzal é Bacharel em violão pela Universidade Federal de Minas Gerais (UFMG), na classe do professor Fernando Araújo, Mestre em Performance pela Universidade Federal da Bahia (UFBA), sob orientação do professor Dr. Mário Ulloa e Doutor em Educação Musical também pela UFBA, orientado pela professora Dra. Cristina Tourinho. Possui trabalhos como concertista, tocando no Theatro São Pedro em Porto Alegre e no Festival Internacional de Inverno de Domingos Martins, entre outros. Como pesquisador, publicou artigos em periódicos, capítulos de livro e lançou um livro recentemente sobre performance musical. Em 2009, concluiu um estágio de sete meses de pesquisa em música na Universidade Católica Portuguesa, na cidade do Porto, sob orientação da professora Dra. Daniela Coimbra. Atualmente é professor Adjunto no Departamento de Artes e coordenador do Núcleo de Humanidades da Universidade Federal do Maranhão (UFMA).

Guilherme Augusto de Ávila iniciou sua graduação na Universidade Federal do Rio Grande do Sul (UFRGS) e concluiu seu bacharelado em violão pela Universidade Federal de Minas Gerais (UFMG), na classe do professor Fernando Araújo. É Mestre em Performance pela Universidade Federal da Bahia (UFBA), sob orientação do professor Dr. Mário Ulloa. Participou de master-classes com importantes violonistas, entre eles Fábio Zanon e Eduardo Isaac. Atuou diversas vezes como concertista, realizando recitais em diversas cidades brasileiras. Como pesquisador, possui publicações em simpósios nacionais e internacionais. Foi professor Substituto da Universidade Estadual do Maranhão (UEMA) e também da Universidade Federal do Maranhão (UFMA). Atualmente é professor Assistente e chefe do Departamento de Artes da UFMA. 